\title{
Development of infant ear asymmetries for speech and music
}

\author{
CATHERINE T. BEST \\ Haskins Laboratories, New Haven, Connecticut 06511 \\ and Teachers College, Columbia University, New York 10027 \\ HARRY HOFFMAN \\ North Dakota State University, Fargo, North Dakota 58102
}

and

BRADLEY B. GLANVILLE

California State University, Chico, California 95926

\begin{abstract}
Groups of 2-, 3-, and 4-month olds were tested for dichotic ear differences in memory-based phonetic and music timbre discriminations. A right-ear advantage for speech and a left-ear advantage (LEA) for music were found in the 3-and 4-month-olds. However, the 2-month-olds showed only the music LEA, with no reliable evidence of memory-based speech discrimination by either hemisphere. Thus, the responses of all groups to speech contrasts were different from those to music contrasts, but the pattern of the response dichotomy in the youngest group deviated from that found in the older infants. It is suggested that the quality or use of lefthemisphere phonetic memory may change between 2 and 3 months, and that the engagement of right-hemisphere specialized memory for musical timbre may precede that for left-hemisphere phonetic memory. Several directions for future research are suggested to determine whether infant short-term memory asymmetries for speech and music are attributable to acoustic factors, to different modes or strategies in perception, or to structural and dynamic properties of natural sound sources.
\end{abstract}

The existence of a neurobiological dichotomy in human auditory perception, which distinguishes at least some qualities of spoken language from most nonlinguistic auditory events, is strongly implied by the pattern and incidence of functional cerebral asymmetries in adults, particularly as revealed through dichotic ear advantages (e.g., Gordon, 1970; Kimura, 1964; Shankweiler, 1966; Studdert-Kennedy \& Shankweiler, 1970). In light of the strong pattern of adult asymmetries, at least in right-handers (for review, see Levy, 1980), functional brain lateralization might be expected to appear very early in develop-

Parts of these data were presented at the 1st International Conference on Infant Studies, in Providence, Rhode Island (March 1978). Completion of the work was supported in part by NINCDS Postdoctoral Fellowship Grant NS5085 to the first author, NIH Grant HD01994 to Haskins Laboratories, and laboratory support to the third author from North Dakota State University, Fargo. We thank the following people for thoughtful discussions and comments on earlier versions of this paper: Hiram E. Fitzgerald, Terry G. Halwes, Lauren J. Harris, Jerre Levy, Kristine MacKain, Michael Studdert-Kennedy, Steven S. Braddon, and Robert Bundy. We also thank Patrick K. Ackles for statistical and computer advice. We are especially indebted to the infants and their parents for their involvement and sincere interest. Please address reprint requests to the first author at Box 142, Teachers College, Columbia University, New York, New York 10027. ment. That is, it may contribute to the ontogeny of differentiated human abilities, especially the acquisition of communicative vs. other skills. Even prelinguistic infants should show asymmetries in their perceptual abilities, since these would serve as the foundation for the more complex lateralized functions found later in life. In addition, early age changes in perceptual and behavioral organization might be associated with changes in the manifestation of functional cerebral asymmetries.

If the logic is correct that early brain lateralization contributes to the development of human abilities, Lenneberg's (1967) earlier claims about its ontogeny are surprising. He proposed that left-hemisphere language dominance first appears around 2 years of age, after the normal onset of language use, and then continues to strengthen in degree until adult-like lateralization is attained during adolescence. However, recent studies of unilateral cortical damage in infancy support prelinguistic lateralization-early left hemisphere injury does disturb aspects of syntactic language abilities more often than right injury, while the latter disturbs visuospatial development (e.g., Dennis \& Kohn, 1975; Dennis \& Whitaker, 1976; Hécaen, 1976; Kohn \& Dennis, 1974). In addition, young children with only partial left-hemisphere injury 
often retain language functions in the undamaged areas of the left hemisphere, rather than developing language in the intact right hemisphere (Milner, 1974; Rasmussen \& Milner, 1977).

While these clinical cases support early brain lateralization, they may misrepresent normally developing brain function, because substantial behavioral and neural reorganization occur in response to early damage. Nonetheless, studies of cerebral asymmetries in normal children have provided overwhelming support for lateralization in cerebral functioning by at least the preschool years (e.g., Kinsbourne \& Hiscock, 1977; Witelson, 1977). In the auditory modality, the adult pattern of right-ear advantage (REA) for verbal stimuli and left-ear advantage (LEA) for musical, environmental, and animal sounds, respectively implying left- and right-hemisphere superiority, has been found in dichotic tasks with children as young as 21/2 years (e.g., Bever, 1971; Kimura, 1963; Knox \& Kimura, 1970). Note, however, that these data do not extend young enough to refute Lenneberg's (1967) claim that lateralization first appears only around 2 years.

More crucial to the prelinguistic lateralization issue, auditory asymmetries have been found in very young infants. The auditory evoked response (AER) to speech stimuli is larger over the left auditory association cortex, and the AER to acoustically complex nonspeech stimuli is larger over the right, in infants as young as a few days old, generally paralleling the adult pattern of neurocortical asymmetries (Molfese, Freeman, \& Palermo, 1975; Molfese \& Molfese, 1979a, 1979b; Molfese, Nunez, Seibert, \& Ramaniah, 1976). Certain asymmetrical responses to speech may exist even prior to normal birth, since they are found in neonates born 4-6 weeks before full term (Molfese \& Molfese, 1980; Segalowitz \& Chapman, 1980). As for dichotic listening, young infants showed an REA for detecting speech contrasts and an LEA for musical timbre contrasts when short interstimulus intervals (ISIs) were used in a high-amplitude sucking (HAS) habituation/dishabituation test (Entus, 1977). Moreover, Glanville, Best, and Levenson (1977) found the same dichotic ear asymmetry pattern in 3-month-olds on a more demanding cardiac orienting (OR一attention-related heart rate deceleration) habituation task, whose long ISIs required the infants to use short-term memory for making speech and music discriminations.

The human neocortical hemispheres thus appear to be functionally asymmetrical very early in life. Yet, a complete picture of the relationship between cerebral lateralization and perceptual ontogeny calls for evidence regarding changes in asymmetrical functioning during early infant development. Theoretical views on this issue have diverged widely. Kinsbourne and Hiscock (1977) argue that brain lateralization exists early and remains static in character and strength during development. Others, however, contend that while some form of lateralization is present early, asymmetries for various abilities emerge only as those abilities mature (e.g., Witelson, 1977). Alternatively, some researchers have claimed that specialized right-hemisphere functions dominate in early development (e.g., Brown \& Jaffe, 1975; Crowell, Jones, Kapuniai, \& Nakagawa, 1973; Taylor, 1969), or conversely that left-hemisphere specialization precedes that for the right (e.g., Corballis \& Morgan, 1978). Unfortunately, extant empirical work cannot resolve the controversy, because there has been little systematic developmental research on infant cerebral asymmetries. Although both Entus (1977) and Molfese et al. (1975) studied a fairly wide age range ( 3 weeks to 10 months), their statistical analyses were based on small numbers of infants at each age and were relatively insensitive to age differences (e.g., mediansplit $t$ tests).

An important step toward tracing the early ontogeny of lateralized speech perception has been taken by Molfese and Molfese (1979a, 1979b). They found differences between 2- and 5-month-olds in asymmetrical AER patterns to voicing and place-ofarticulation distinctions among stop consonants. However, since age differences for nonspeech asymmetries were not studied, their findings do not speak to differential development of right- and left-hemisphere specialization. Direct age-related comparisons between speech and music asymmetries would still be needed. Furthermore, data obtained through a different experimental technique, which might reflect more complex processes than can currently be inferred from infant AER measures, would be valuable. Therefore, we investigated infant dichotic memory abilities in 2-, 3-, and 4-month-olds, using the Glanville et al. (1977) procedure.

Based on previous infant dichotic findings (Entus, 1977; Glanville et al., 1977), we expected that, by at least 3 months of age, infants would show a rightear advantage (REA) for discriminating among speech syllables and a left-ear advantage (LEA) for discriminating among musical instruments playing a single note. However, predictions about lateralized perceptual memory in 2-month-olds were more difficult. The work of D. L. Molfese and his colleagues $(1975,1976,1979 a, 1979 b)$ indicates that although 2-month-olds show left-hemisphere neurocortical specialization for speech, their asymmetry pattern differs from that of 5-month-olds, at least for some aspects of consonant processing. The recent failure of Vargha-Khadem and Corballis (1979) to replicate, in 2month-olds, the speech discrimination REA that Entus obtained with infants averaging $2 \frac{1}{2}$ to 3 months of age (Vargha-Khadem \& Corballis found, instead, equal discrimination by both ears) also suggests a possible difference between the speech processing asymmetries of 2-month-olds and older infants. 
Recent speech-perception research suggests that infants under 3 months of age might fail at memorybased consonant discriminations, such as those entailed by the Glanville et al. (1977) dichotic procedure. Infants younger than 3-4 months fail to discriminate certain phonetic contrasts when demands are placed on short-term memory (long ISIs), even though they discriminate the same contrasts under less demanding (short ISI) conditions (Leavitt, Brown, Morse, \& Graham, 1976; Leavitt, Morse, Brown, \& Graham, 1973; Morse, 1978) similar to those used by Entus and Vargha-Khadem. If infants under 3 months are deficient in phonetic memory, then, as a result of a floor effect in phonetic memory, 2-month-olds should fail to show a speech REA on a memory-based discrimination task: that is, they should show no evidence of memorybased consonant discrimination by either hemisphere.

Predictions about dichotic timbre discrimination by 2 -month-olds pose even greater difficulties. With the exception of the somewhat older subjects in the Entus (1977) and Glanville et al. (1977) studies, we know of no data on young infants' discrimination of musical timbre or of any theoretical perspective on early timbre perception. Unfortunately, neither Molfese and his co-workers nor Vargha-Khadem and Corballis tested asymmetries for music perception. One possibility is that 2 -month-olds have a general, rather than speech-specific, auditory memory deficiency. That is, they might fail to discriminate music or speech changes, with either hemisphere, under long-ISI conditions. In fact, 2-month-olds might even have greater memorial difficulty with music than with speech, given that human speech is especially potent over other sounds for affecting young infants' behavior (e.g., Condon \& Sanders, 1974; Eisenberg, 1968; Hutt, Hutt, Lenard, von Bernuth, \& Muntjewerff, 1968; Leavitt et al., 1973), and the recent theoretical proposal for a left-right gradient in human laterality development (Corballis \& Morgan, 1978). On the other hand, Leavitt et al., (1976) tested 6-week-olds in a cardiac habituation study of sound-pattern discrimination, and found evidence for earlier cortical involvement in the detection of pulsed-tone frequency contrasts than in the detection of phonetic contrasts. In line with this report of greater maturity for the early processing of nonspeech than of speech, the suggestion that the right hemisphere is more "active" than the left in early infancy (Brown \& Jaffe, 1975; Crowell et al., 1973; Taylor, 1969) would predict a music LEA to be found earlier than a speech REA, perhaps in our 2-month-olds.

\section{METHOD}

\section{Subjects}

Forty-eight 2-, 3-, and 4-month-olds (eight infants per age $x$ sex subgroup) completed the study. The mean ages were, respec- tively: 62.47 days $(S D=3.37$, range $=55-66), 92.69$ days $(S D$ $=4.30$, range $=87-103)$, and 123.5 days $(S D=4.31$, range $=115$ 130). The subjects were recruited via mailings to recent parents listed in local newspaper birth announcements, and were screened for birth complications; none were on medication at time of testing. In all, 132 infants participated in the study. Failure to complete the experiment resulted from infant crying (for 2-, 3-, and 4-month-olds, respectively: 9,12 , and 11 subjects), sleeping $(5,3$, and 4 subjects), excessive squirming $(0,5$, and 6 subjects), and illness $(0,0$, and 2 subjects), and from parental interference $(1,0$, and 3 subjects), equipment failure (1, 0 , and 3 subjects), and experimental error, including infants whose age at testing fell outside the limits for their group (3, 8, and 9 subjects). Excluding the last three factors, the infant state-related rejection rate was 56 infants of 104 tested, or $53.9 \% .^{1}$

\section{Stimuli}

The syllables used in the dichotic speech tests were computer synthesized three-formant tokens of each of the six English stop consonants followed by the vowel $/ \mathrm{a} /$. All were highly identifiable to adults, according to prior testing. Each syllable was $350 \mathrm{msec}$ long, and had initial 45 -msec formant transitions, without burst cues, to distinguish place of articulation. Speech set $\mathbf{A}$ consisted of /ba/ and /da/ as the dichotic habituation pair and /ga/ as the test stimulus. Speech set $B$ consisted of $/ \mathrm{pa} /$ and $/ \mathrm{ta} /$ as the habituation pair and $/ \mathbf{k a} /$ as the test stimulus.

Music-note stimuli were $600 \mathrm{msec}$ (75-msec rise and fall times) Minimoog-synthesized renditions of the note $\mathbf{A}$ above middle $\mathbf{C}$ $(440 \mathrm{~Hz})$ by various musical instruments. Music-note set $A$ had piano and brass stimuli as the habituation pair, with reed as the test stimulus; set B had organ and string as the habituation pair, with flute as the test stimulus. ${ }^{2}$

\section{Procedure}

Each infant completed four dichotic cardiac orienting (OR) habituation/dishabituation tests during one session, each approximately $31 / 2 \mathrm{~min}$ long: a right-ear and a left-ear test for phonetic discrimination, and for musical timbre discrimination. Cardiac responses were monitored on a Grass Model 7 polygraph via two Beckman biopotential recording electrodes taped to the infant's chest, 1 in. $(2.54 \mathrm{~cm})$ above each nipple, and one ground lead taped to the infant's left earlobe. Raw electrocardiograms (ECGs) were collected through a Grass Model 7P122 preamplifier, while heart rate in beats per minute (BPMs) was simultaneously recorded through a Grass Model 7P4 tachograph preamplifier.

The procedure was that used by Glanville et al. (1977). Each test consisted of 10 trials; a single dichotic auditory stimulus was presented on each trial at $68 \mathrm{~dB}$ re: $.0002 \mathrm{dyne} / \mathrm{cm}^{2}$ (scale $\mathrm{C}$, Model 2203 Brüel-Kjaer sound-level meter) over Sennheiser HD400 open-air headphones. To avoid temporal conditioning, intertrial intervals varied randomly from 15 to $25 \mathrm{sec}(M=20 \mathrm{sec})$. During each of the first nine trials of each test, the dichotic habituation pair was presented once; the right ear always received one pair member while the left ear simultaneously received the other. On the 10th trial, one ear again received its habituation stimulus while the test ear received the novel stimulus. The cardiac OR was expected to habituate during these first nine trials, so that response recovery on the test trial would denote dishabituation and, thereby, detection of the stimulus change. For one test within a stimulus type, the novel stimulus was presented to the left ear; for the other, it was presented to the right ear. Test presentation orders were counterbalanced between subjects; the order for ear tested on Trial 10 was counterbalanced within subjects. There was a pause of at least $1 \mathrm{~min}$ between tests within each stimulus type to reverse the headphone channels, and a pause of at least 5 min between test blocks for the two stimulus types. If necessary, longer breaks were taken to maintain or return the infant to an alert, nonfussy state. Testing thus took a minimum of $20 \mathrm{~min}$, with an additional 10-15 min to acclimate the infants to the lab and prepare them for heart rate recording. The average in-lab time was $45 \mathrm{~min}$ (range $=30-60 \mathrm{~min}$ ). 


\section{Data Reduction}

The heart rate response of interest was an orienting response (OR), or stimulus-elicited phasic deceleration. Mean heart rate (BPM) was calculated on each trial for the 5-sec prestimulus interval and the 5-sec poststimulus interval. Five-second intervals were chosen because, in the second-by-second course of poststimulus cardiac deceleration in young infants (1 1/2- to 4-month), peak deceleration is typically achieved around the fifth poststimulus second (Graham \& Jackson, 1970). Analyses based on these data are informative about whether heart rate decelerated significantly below prestimulus levels following a stimulus presentation, and are referred to as the pre-post analyses. For comparisons of the magnitude of ORs, heart rate difference scores were calculated on each trial by subtracting the poststimulus mean BPM from the prestimulus mean. Positive difference scores reflect cardiac deceleration (OR).

The predictions made in the introduction dictated the following planned comparisons: First, to test for habituation during the first nine trials of all tests, an overall analysis of variance (ANOVA) was carried out on the difference score data for stimulus type (speech or music) $\times$ trial (1-9) $\times$ gender $\times$ age. A trial effect without interactions was expected; to assure that the effect reflected a decrement in poststimulus deceleration (true habituation), rather than a tonic increase in prestimulus heart rate, a second ANOVA was run on the pre-post data for stimulus type $x$ ear $x$ trial $\times$ gender $\times$ age $\times$ pre-post. Here a trial $\times$ pre-post interaction was expected, with simple effects tests (Kirk, 1968) showing a poststimulus deceleration on Trial 1 but not on Trial 9, indicating habituation.

Second, to assess replication of the Glanville et al. (1977) results in our overall discrimination data, we analyzed ear and stimulus differences in recovery of cardiac orienting on Trial 10 relative to Trial 9, and in magnitude of Trial 10 deceleratory responses. A trial $\times$ ear $\times$ stimulus type interaction was expected in the Trial 9 vs. Trial 10 difference score ANOVA, with simple effects supporting significant response recovery only for right-ear speech and leftear music changes on Trial 10. Furthermore, a Trial 10 pre-post ANOVA was expected to yield a stimulus type $\times$ ear $\times$ pre-post interaction, the simple effects of which would support a speech REA and music LEA.

Third, planned comparison ANOVAs were carried out to test the age-related predictions about Trial 10 dishabituation patterns (see Introduction). Because we had predicted a speech REA and music LEA in both the 3-and the 4-month-olds, and weak evidence of speech and/or music discrimination without actual reversal of ear differences in 2-month-olds, age interactions could not be expected in the overall test trials ANOVAs, given the standard computational formulas for MS and error terms. In one published treatment of this type of overall ANOVA problem, Hale (1977) has shown that the significance of real age differences representing a monotonic trend in some factor over more than two age levels (as was the case for our predictions) is severely underestimated by overall ANOVAs using age as a factor, which greatly increases the probability of Type II error. Moreover, our specific age predictions were keyed to the strength of Trial 10 dishabituations within each age group. The appropriate tests, therefore, were planned comparison difference score ANOVAs on Trial 9 vs. Trial 10 data, and pre-post ANOVAs on Trial 10, carried out separately for each age group. Simple effects tests were expected to show significant dishabituation only for the right-ear speech and left-ear music tests in the 3- and 4-month groups, but were not expected to support speech dishabituation for either ear in 2month-olds, with either a music LEA or a lack of music dishabituation."

\section{RESULTS}

\section{Overall Group Analyses}

Habituation trials. The significant trial effect for the Trials 1-9 ANOVA on difference scores $[F(8,336)$

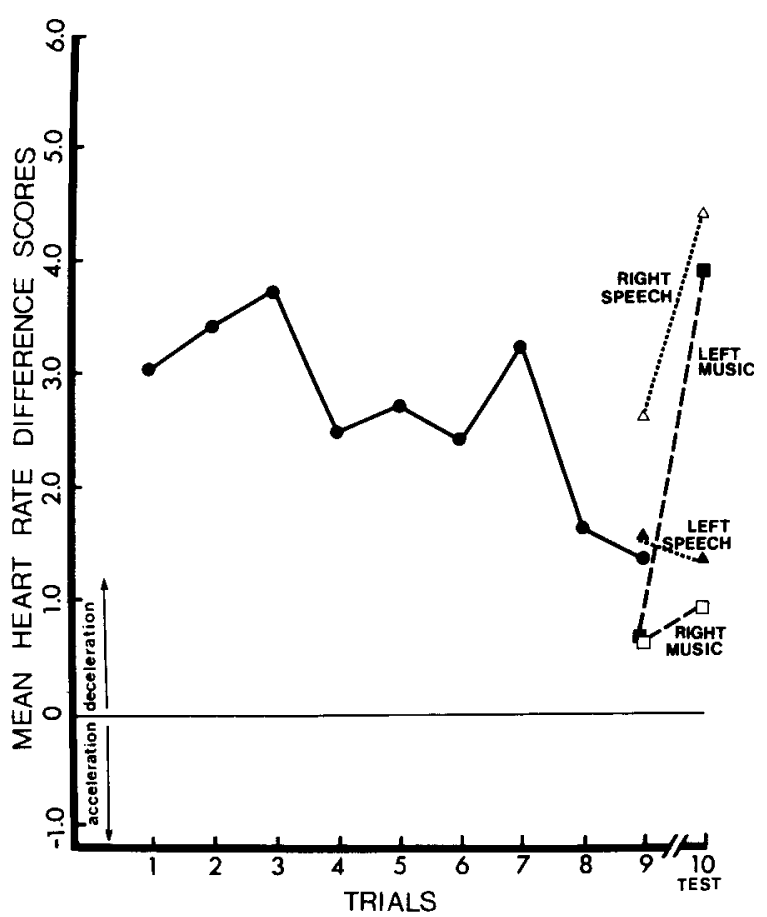

Figure 1. Habituation of the cardiac OR over the habituation trials for all conditions, and recovery of the OR on the test trial for each condition.

$=2.27, \mathrm{p}<.025]$ suggested reliable habituation (see Figure 1). The predicted trial $\times$ pre-post interaction in the Trials 1-9 pre-post ANOVA was also significant $[F(16,336)=3.18, p<.0001]$. While prestimulus heart rate remained relatively constant, the magnitude of poststimulus deceleration diminished over trials (see Figure 2). Also as predicted, simple effects tests revealed a significant cardiac OR on Trial 1 $[\mathrm{F}(1,378)=9.31, \mathrm{p}<.005]$, but not on Trial 9. The habituation curve was not significantly affected by ear, gender, stimulus type, ${ }^{4}$ or age. ${ }^{3}$

Test trial. Strong support for a speech REA and music LEA in dishabituation patterns was provided by the Trial 10 difference score ANOVA and the Trial 9 vs. Trial 10 pre-post ANOVA. The stimulus type $\times$ ear interaction for Trial $10[F(1,42)=10.47$, $\mathrm{p}<.003$ ] suggested an REA for phonetic discriminations that was supported by simple effects tests $[F(1,84)=5.31, \mathrm{p}<.025]$, along with a musical timbre LEA $[F(1,84)=4.98, p<.05]$ (see right-hand side of Figure 1). Moreover, the right-ear stimulus change produced a larger Trial $10 \mathrm{OR}$ for speech than for music tests $[F(1,84)=7.88, p<.01]$, whereas the leftear stimulus change produced a larger $O R$ for music than for speech tests $[F(1,84)=4.11, p<.05]$.

That the Trial 10 stimulus type $\times$ ear pattern truly reflected asymmetries in dishabituations was supported by the significant stimulus type $\times$ ear $\times$ trial (9 vs. 10$) \times$ pre-post interaction $[\mathrm{F}(1,42)=4.25$, $\mathrm{p}<.05]$. There were no reliable cardiac ORs on 


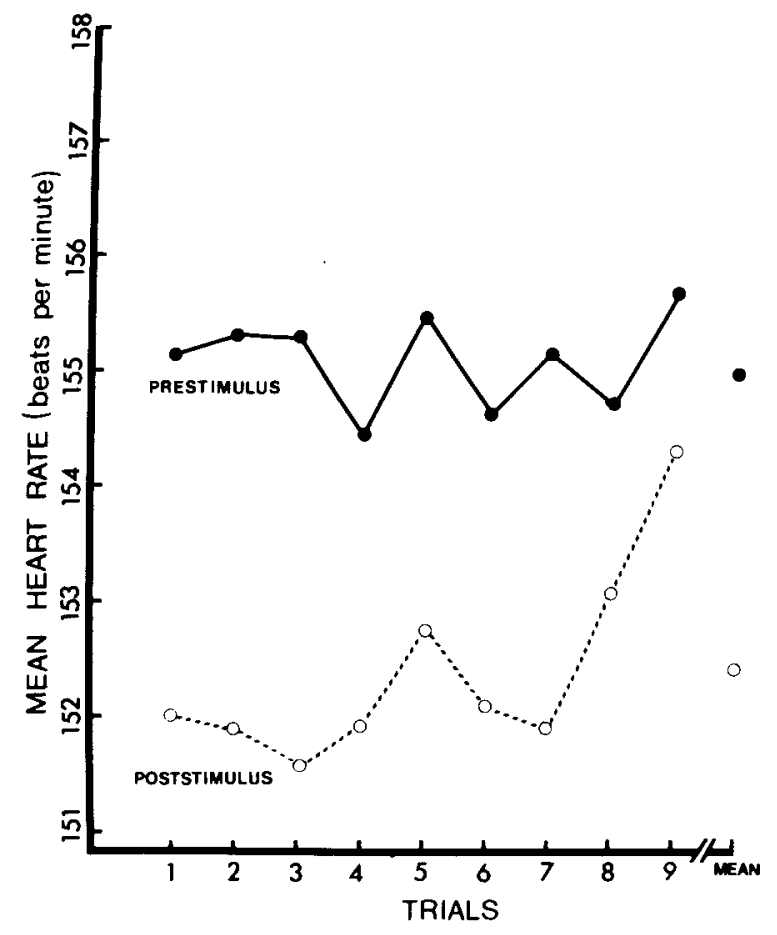

Figure 2. Mean heart rate in BPM for the 5-sec prestimulus period and the 5-sec poststimulus period on each trial, and the grand mean for all habltuation trials.

Trial 9 for any test; habituation was equivalent across tests. Significant dishabituation on Trial 10 was found only for the right-ear speech test $[F(1,84)=$ $8.69, p<.005]$ and the left-ear music test $[F(1,84)$ $=6.71, \mathrm{p}<.025]$.

\section{Within-Age Analyses}

Two-month-olds. The dishabituation pattern for the 2-month-olds shows a right-hemisphere superior- ity for memory-based musical timbre discrimination, but a lack of reliable phonetic discrimination by either hemisphere (n.s. REA tendency-left-hand panel of Figure 3). They showed equal cardiac habituation by Trial 9 of all tests. Yet the simple effects tests of the Trial 10 stimulus type $\times$ ear $\times$ pre-post interaction $[F(1,14)=4.19, p<.05]$ revealed a significant cardiac deceleration to the test stimulus for the left-ear music test alone $[F(1,28)=4.21, p<.05]$. The Trial 10 pre-post differences for the other three conditions fell far short of significance. (For response patterns of individual infants, see Appendix. It should be noted that although the speech REA for this age group was nonsignificant, six individuals did show speech discrimination with an REA.)

Three-month-olds. The 3-month-olds (center Figure 3) showed a phonetic REA and a musical timbre LEA. Simple effects tests on the Trial 9 vs. Trial 10 difference score trial $\times$ ear $\times$ stimulus type interaction $[F(1,14)=3.39, p<.08]$ found Trial 10 dishabituation only for the right-ear speech test $[F(1,28)$ $=8.36, \mathrm{p}<.01]$ and the left-ear music test $[\mathrm{F}(1,28)$ $=11.19, \mathrm{p}<.005]$.

Four-month-olds. This age group also showed a speech REA and music LEA, according to the significant Trial 10 stimulus type $\times$ ear $\times$ period interaction $[F(1,14)=4.74, p<.05]$ (right-hand panel, Figure 3). Simple effects tests found cardiac OR dishabituation only on the left-ear music test $[F(1,28)$ $=5.73, \mathrm{p}<.025]$ and the right-ear speech test $[\mathrm{F}(1,28)$ $=12.05, \mathrm{p}<.001]$.

\section{DISCUSSION}

This study replicated and extended the earlier Glanville et al. (1977) study of 3-month-olds. Under conditions requiring short-term retention of stimulus qualities essential for detecting speech and music
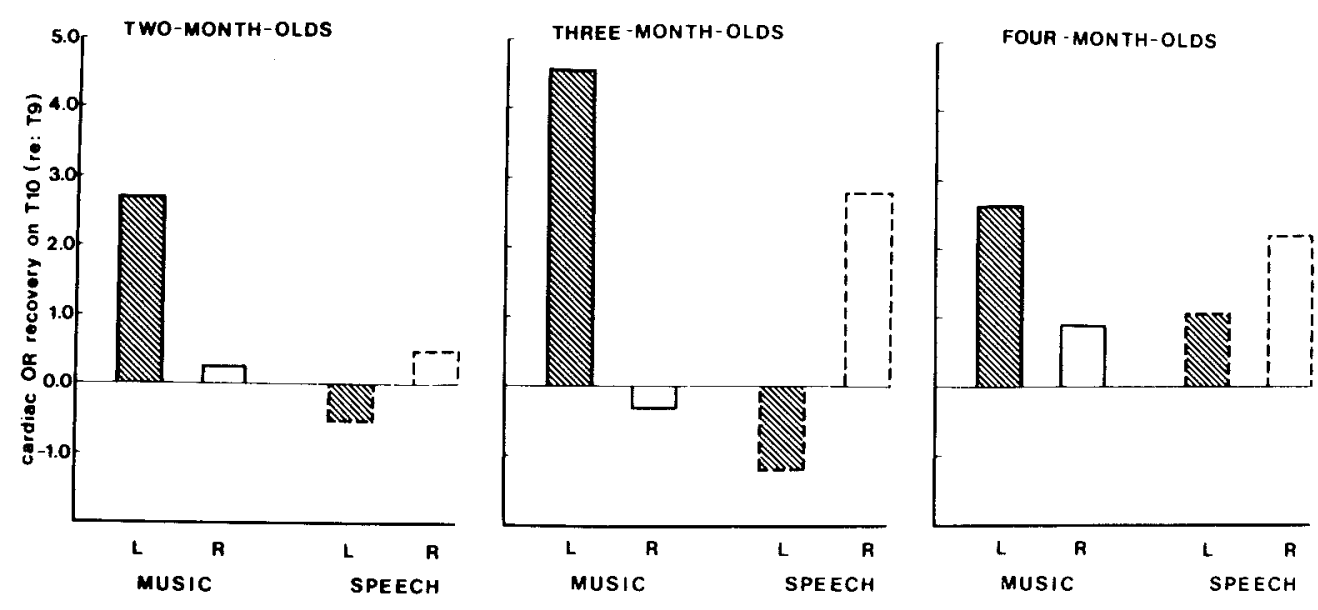

Figure 3. Magnitude of $O R$ recovery for the test trial in each condition, relative to the cardiac response on the last habituation trial, In the 2-, 3-, and 4-month-olds. 
note contrasts, 3- to 4-month-olds showed a lefthemisphere advantage for phonetic discriminations, and 2- to 4-month-olds showed a right-hemisphere advantage for music timbre discriminations. Two important conclusions can be drawn: (1) Evidence of short-term memory for phonetic information becomes generally reliable sometime between 2 and 3 months of age, and in this it is the left hemisphere that shows the major age-related improvement, whereas short-term memory for music timbre is reliable and right hemisphere biased at least by 2 months; (2) 4-, 3-, and even 2-month-olds at least roughly dichotomize their perceptual responses to sounds according to two categories adults perceive to be fundamentally different, speech vs. music, despite the fact that both stimulus types provide complex patterns of acoustic information. Both findings may have implications for understanding perceptual ontogeny and lateralization. We will turn now to a discussion of the first.

\section{Early Age Differences}

The age difference we found in infants' memorybased speech vs. music discriminations can help decide among the various theoretical perspectives on development of lateralization that were summarized in the introduction. That 2-month-olds differed from the older groups in their auditory memory asymmetries for detecting contrasts in the two stimulus types militates against the Kinsbourne and Hiscock (1977) argument that brain lateralization is a unitary trait that remains stable throughout ontogeny. Moreover, the age change in speech REA but not in music LEA runs counter to the Corballis and Morgan (1978) claim for a left-right maturational gradient in human laterality, at least for auditory memory development. Instead, the results seem most supportive of earlier right- than left-hemisphere advantages (Brown \& Jaffe, 1975; Crowell et al., 1973; Taylor, 1969), for the aspects of auditory short-term memory we tested.

We must stress, however, that the 2-month-olds' failure to show a group left-hemisphere speech advantage actually reflects a floor effect in phonetic memory ability. Witelson (1977) has argued that one cannot logically expect to detect asymmetrical specialization for an undeveloped ability. It would be incorrect to conclude that 2 -month-olds generally lack functional left-hemisphere specialization. That conclusion would require significant evidence of speech discrimination in the absence of an ear asymmetry. In fact, the converse of Witelson's argumentthat hemispheric specialization becomes evident as a trait becomes reliable-finds some support from the individual differences we report in the Appendix. Among the small number of 2-month-olds who did discriminate the speech contrasts, the majority showed an REA (67\%). Stronger support for this argument, however, would require longitudinal research starting earlier than 2 months.

Our age difference findings relate specifically to auditory memory and its asymmetries, and therefore to only one aspect of functional lateralization, which may best be conceived of as an increasingly complex (ontogenetically) or multidimensional, rather than static unidimensional, trait. Indeed, other asymmetry measures have uncovered left-hemisphere functional superiorities before 2 months. Molfese's work has clearly established a left-hemisphere advantage in the AER to human speech, even among normal and preterm newborns. Moreover, in contrast to our evidence of earlier reliable right- than left-hemispherespecialized auditory memory, Segalowitz and Chapman (1980) found that exposure to taped conversations reduced right-sided limb tremor in very young premature neonates, whereas music exposure had no tremor-reduction effect on limbs of either side. Their findings suggest that speech-related left-hemisphere inhibition of contralateral tremor may mature earlier than right-hemisphere inhibitory control. There is thus no unambiguous answer to the question "When does functional specialization of each cerebral hemisphere begin?" To get a clear answer regarding ontogeny, the question must be clarified by asking, at least, ". . f for what ability?" In addition, attention must be paid to the nature of the tasks and stimuli used, the behavioral responses involved, and the developmental context of the subject's normal functioning in his/her natural environment.

Since infants 2 months old and younger do show left-hemisphere advantages on some tasks in other research, our results cannot define a lower age limit on general left-hemisphere specialization. However, they suggest age and stimulus differences in auditory memory that do relate to the functional specialization of the two hemispheres during early development. Why might right-hemisphere-biased memory for musical timbre qualities be evident earlier than left-hemisphere memory for phonetic information? Although the present study cannot answer this question, some insights may be derived from other research, which may offer suggestions for further exploration of the underlying nature of hemispheric asymmetries in developing perceptual and cognitive abilities. For example, as we indicated earlier in the paper, infant speech perception research suggested that a change in memory for phonetic information occurs sometime after 2 months. Infants as young as 1 month can detect a contrast in place of articulation (e.g., /b/ vs. /d/), or in voice onset time (e.g., /p/ vs. /b/), for a variety of consonants, as long as the syllables are presented at a rapid rate (short ISI) of 1 or $2 / \mathrm{sec}$ (e.g., Cutting \& Eimas, 1975; Eimas, Siqueland, Juszcyk, \& Vigorito, 1971; Trehub \& Rabinovitch, 1972). Infants this young, however, 
apparently fail at detecting the same phonetic contrasts if the ISIs are lengthened, so that short-term retention of stimulus properties is required. Only by 3 or 4 months do infants discriminate among these consonants under short-term memory demands (e.g., Miller, Morse, \& Dorman, 1977; Morse, 1978). This combined information led to our prediction that 2-month-olds might have difficulty discriminating phonetic contrasts under the memory demands of our task, and hence fail to show a speech REA.

Our 2-month-olds did fail to reliably detect consonant contrasts with either hemisphere under shortterm memory demands. However, under much lower memory demands, the 2-month-olds in the VarghaKhadem and Corballis study (1979) discriminated similar contrasts, and did so equally well with both hemispheres, suggesting perceptual discrimination without asymmetry. In contrast to the latter suggestion, the somewhat older infants in Entus' (1977) study did show an REA in speech discrimination, indicating a left hemisphere advantage, under the same low memory demands. Taken together, these three findings suggest an auditory memory "deficit" in infants under $2 \frac{1 / 2}{2}$ to 3 months of age that is specific to left-hemisphere memory for phonetic information. That 2-month-olds may have a phonetic memory deficit is not necessarily at odds with their ability to discriminate phonemes under lower memory demands. The latter ability requires merely the registration of acoustic contrast, which could occur at a subcortical or peripheral level, and need not require asymmetrical neocortical involvement (see, e.g., phonetic discrimination in an anencephalic infant: Graham, Leavitt, Strock, \& Brown, 1978).

In the introduction, we suggested that age changes in the manifestation of cerebral asymmetries might be associated with periods of perceptual and behavioral reorganization. Our data, in conjunction with those of Entus (1977), Vargha-Khadem and Corballis (1979), and the 2- vs. 5-month difference in AER asymmetries to phonetic information found by $D$. $L$. Molfese and his colleagues (1979a, 1979b), indicate that between 2 and 3 months a change may occur in asymmetrical neocortical involvement in perception and memory for speech. Such a change would be consistent with the concurrent changes in basic phonetic vs. nonspeech memory abilities discussed earlier (e.g., Leavitt et al., 1973, 1976; Morse, 1978). In fact, there are many other biobehavioral and perceptual changes around 2-3 months (Emde \& Robinson, 1976), particularly in the infant's movement toward more truly social-communicative efforts in interactions with others (e.g., Trevarthen, 1977a, 1977b), which provide converging support for the notion that it is a period of important perceptual reorganization.

\section{Two Categorles in Infant Auditory Perception}

The findings indicate not only that there are early age differences in the manifestation of infant audi- tory memory asymmetries, but also that even very young infants can distinguish between the classes of speech and music, and show differentiated behavior toward them. The latter observation raises several questions that are theoretically relevant for auditory perception in adults, and especially for the nature of perceptual development. For example, how do young infants, with their limited auditory experience and lack of "meaningful" language, perceptually distinguish speech from music? Also, what might be the underlying mechanisms for their behavioral differentiation of speech vs. music, including that seen in studies of infant hemispheric asymmetries? Although the present research was not directly addressed to these issues, they are important ones for future research to confront if the source of infant cerebral asymmetries is to be understood, and if they are to speak to more basic theoretical issues in perceptual development and differentiation.

Exploration of perceptual differences for speech vs. music in adults and infants, particularly those differences underlying cerebral asymmetries, should probe both the qualities of the perceptual responses and the contribution of stimulus and task characteristics. Possible avenues for this research effort are suggested by three contemporary frameworks in the study of perceptual phenomena, derived primarily from work with adults; the three may or may not prove to be mutually incompatible. The first approach emphasizes psychoacoustic analyses of stimuli. Its goal is to uncover the relationship between characteristics of the perceptual response and the acoustic properties of the auditory stimuli perceived. This general approach has been applied to the study of speech (e.g., Oden \& Massaro, 1978) and music timbre perception (e.g., Grey, 1977; Grey \& Gordon, 1978; Grey \& Moorer, 1977; Miller \& Carterette, 1975; Wessel, Smith, \& Ehresman, 1978), including perceptual asymmetries in adults and infants (e.g., Best, 1978; Blechner, 1977; Cutting, 1974; Schwartz \& Tallal, 1980). The second approach, a more cognitive one, focuses on processing strategies or perceptual modes for handling incoming information, which are theoretically independent of low-level stimulus attributes except as the latter might bias subjects toward a particular strategy or mode. This perspective has been taken in studies of speech (e.g., Best, Morrongiello, \& Robson, 1981; Dorman, Studdert-Kennedy, \& Raphael, 1977; Fitch, Halwes, Erickson, \& Liberman, 1980) and music perception as well as visual perception, and has included perceptual asymmetries (e.g., Bartholomeus, 1974; Bever, 1978; Bever \& Chiarello, 1974; Cohen, 1973; Levy-Agresti \& Sperry, 1968; Natale, 1977; Seamon \& Gazzaniga, 1973; Semmes, 1969; Spellacy \& Blumstein, 1970; Tomlinson-Keasey, Kelly, \& Burton, 1978; Veroff, 1978). The third contemporary perceptual framework, which is less well known, is that 
provided by ecological psychologists (e.g., Gibson, 1979; Michaels \& Carello, 1981). The focus in this approach is on the perception of the structural and dynamic characteristics of real objects taking part in various transformations over time (events); certain structural and dynamic qualities of sound-producing objects would be directly available in the sounds produced, according to the laws of acoustic physics (for discussions of speech and music acoustics, see Fant, 1960; Roederer, 1973). Although this third approach has not been formally applied to research on cerebral asymmetries, it has been used in research and thinking about speech perception (e.g., Summerfield, 1978) and nonspeech auditory perception (e.g., Jenkins, Note 1; Warren, Note 2), as well as visual perception (e.g., Cutting \& Koslowski, 1977; Johansson, 1973; Lee, 1980) and even infants' perception of natural events (e.g., Bahrick, Walker, \& Neisser, 1981; Dodd, 1979; Ruff, 1980; Spelke, 1979). It would thus seem applicable to further study of the speech vs. music perceptual dichotomy in adults and infants (perhaps to cerebral asymmetries as well-see Fowler, Note 3). At the present time, the contributions of psychoacoustic factors, processing strategies or perceptual modes, and qualities of natural events toward an understanding of the speech-music perceptual dichotomy, and of cerebral asymmetries in adults and infants, awaits substantial empirical (and theoretical) work.

\section{Methodological Considerations}

The paradigm used in this study seems most suited for testing auditory memory asymmetries in 3-montholds (see Appendix), and may lead to a near-ceiling effect for infants of 4 months or older. Our 4-month olds showed some tendency toward carrying out both speech and music discriminations with either hemisphere (see Figure 3), even though statistical analysis of their performance did reveal the predicted ear asymmetries. Also, the method would appear useful for group studies of memory-based asymmetries, but may not be sensitive enough for individual assessments in its present form. Testing of younger infants, or of individuals, might be improved by reducing the ISIs (Morse, 1978) or by increasing the number of habituation trials (McCall \& Melson, 1970).

Methodological modifications of the task might be useful not only for studies of normal preverbal development, but also for studies of developmental language pathologies, especially with subjects from whom a voluntary verbal or motor response cannot be easily obtained (as long as they orient physiologically to the stimuli). For example, auditory perception is difficult to measure in autistic children by other, more traditional means because of their asocial behaviors and failure to use language for interpersonal communication, but this dichotic cardiac procedure has been used successfully with four autistic children (Kodera, Note 4). In fact, the peculiar failure of autistic children to acquire language normally, in the face of apparently intact hearing and auditory processing, has led to the suggestion that autists may either have a dysfunctional left hemisphere or fail to activate the left hemisphere at appropriate times (e.g., Simon, 1975; Takagi, 1972; Tanguay, 1976; Blackstock, Note 5; Levy, Note 6). These suggestions receive converging support from recent computerized axial tomography scan (CAT) research, which has revealed abnormal physical asymmetries of the left and right hemispheres in a substantial proportion of individuals in an infantile autistic sample (Hier, Le May, \& Rosenberger, 1979).

\section{REFERENCE NOTES}

1. Jenkins, J. J. Perception of acoustic events. Invited address at the first Conference on Event Psychology. Storrs, Connecticut, June 1981.

2. Warren, W. H., Jr. Them's the breaks: Acoustic information for breaking and bouncing events. Paper presented at the meeting of the Eastern Psychological Association, Hartford, Connecticut, March 1980.

3. Fowler, C. A. A systems approach to the cerebral hemispheres (Status Report on Speech Research, SR-44). New Haven, Conn: Haskins Laboratories, 1975.

4. Kodera, T. Personal communication, Tulane University, 1977.

5. Blackstock, E. G. Cerebral asymmetry and the development of infantile autism (Report No. 64). Ontario, Canada: York University, 1977.

6. Levy, J. Variations in the lateral organization of the brain. Master lecture presented at the meeting of the American Psychological Association, San Francisco, California, 1977.

\section{REFERENCES}

Bahrick, L. E., Walker, A. S., \& Neisger, U. Selective looking by infants. Cognitive Psychology, 1981, 13, 377-390.

BArtholomeus, B. Effects of task requirements on ear superiority for sung speech, Cortex, 1974, 10, 215-223.

BEsT, C. T. The role of consonant and vowel acoustic features in infant cerebral asymmetries. Unpublished doctoral dissertation, Michigan State University, 1978.

Best, C. T., Mornongiello, B., \& Robson, R. Perceptual equivalence of two acoustic cues in speech and nonspeech perception. Perception \& Psychophysics, 1981, 29, 191-211.

Bever, T. G. The nature of cerebral dominance in the speech behavior of the child and adult. In R. Huxley \& E. Ingram (Eds.), Language acquisition: Models and methods. London: Academic Press, 1971.

Bever, T. G. Broca and Lashley were right: Cerebral dominance is an accident of growth. In D. Caplan (Ed.), Biological studies of mental processes. Cambridge, Mass: M.I.T. Press, 1978.

Bever, T. G., \& Chinkello, R. J. Cerebral dominance in musicians and nonmusicians. Science, 1974, 185, 537-539.

BLECHNER, M. J. Left-ear advantage for sounds characterized by a rapidly varying resonance frequency. Bulletin of the Psychonomic Society, 1977, 9, 363-366.

Brown, J., \& JAFFE, J. Hypothesis on cerebral dominance. Neuropsychologia, 1975, 13, 107-110.

Conen, G. Hemispheric differences in serial vs. parallel processing. Journal of Experimental Psychology, 1973, 97, 349-356.

Condon, W. S., \& Sanders, L. W. Synchrony demonstrated between movements of the neonate and adult speech. Child Development, 1974, 45, 456-462.

Corballis, M. C., \& Moran, M. J. On the biological basis of 
human laterality: 1. Evidence for a maturational left-right gradient. Behavioral and Brain Sciences, 1978, 2, 261-269.

Crowell, D. H., Jones, R. H., Kapuniai, L. E., \& Nakagawa, J. K. Unilateral cortical activity in newborn humans: An early index of cerebral dominance? Science, 1973, 180, 205-208.

Cutrina, J. E. Two left hemisphere mechanisms in speech perception. Perception \& Psychophysics, 1974, 16, 601-612.

Cutring, J. E., \& Eimas, P. D. Phonetic feature analyzers and the processing of speech in infants. In J. F. Kavanaugh \& J. E. Cutting (Eds.), The role of speech in language. Cambridge, Mass: M.I.T. Press, 1975.

Cutting, J. E., \& Kostowski, L. T. Recognizing friends by their walk: Gait perception without familiarity cues. Bulletin of the Psychonomic Society, 1977, 9, 353-356.

Dennis, M., \& KoHn, B. Comprehension of syntax in infantile hemiplegics after cerebral hemidecortication: Left hemisphere superiority. Brain \& Language, 1975, 2, 472-482.

Dennis, M., \& Whitake, H. A. Language acquisition following hemidecortication: Linguistic superiority of the left over the right hemisphere. Brain \& Language, 1976, 3, 404-433.

DoDD, B. Lip reading in infants: Attention to speech presented in- and out-of-synchrony. Cognitive Psychology, 1979, 11, 478-484.

Dorman, M. F., Studdent-Kennedy, M., \& Raphael, L. J. Stop consonant recognition: Release bursts and formant transitions as functionally equivalent context-dependent cues. Perception \& Psychophysics, 1977, 22, 109-122.

Emas, P. D., Siqueland, E., Jusczyk, P., \& Vigorito, J. Speech perception in infants. Science, 1971, 171, 303-306.

Etsenferg, R. B. Auditory behavior in the human neonate: Functional properties of sound and their ontogenetic implications. International Audiology, 1968, 8, 34-45.

Evde, R. N., \& Robinson, J. The first two months: Recent research in developmental psychobiology and the changing view of the newborn. In J. Noshpitz \& J. Call (Eds.), Basic handbook of child psychiatry. New York: Basic Books, 1976.

ENTUs, A. K. Hemispheric asymmetry in processing of dichotically presented speech and nonspeech sounds by infants. In $S$. Segalowitz \& F. A. Gruber (Eds.), Language development and neurological theory. New York: Academic Press, 1977.

Fant, G. Acoustic theory of speech production. The Hague: Mouton, 1960.

Fitch, H. L., Halwes, T., Erickson, D. M., \& Liberman, A. M. Perceptual equivalence of two acoustic cues for stop-consonant manner. Perception \& Psychophysics, 1980, 27, 343-350.

GiBson, J. J. The ecological approach to visual perception. Boston: Houghton-Mifflin, 1979.

Glanville, B. B., Best, C. T., \& Levenson, R. A cardiac measure of cerebral asymmetries in infant auditory perception. Developmental Psychology, 1977, 13, 54-59.

Goodolass, H., \& QuadFAsel, F. A. Language laterality in left-handed aphasics. Brain, 1954, 77, 521-548.

Gondon, H. W. Hemispheric asymmetries in the recognition of musical chords. Cortex, 1970, 6, 387-398.

Graham, F. K., Berg, K. M., Berg, W. K., Jackson, J. C., \& KANTOWITZ, S. R. Cardiac orienting responses as a function of age. Psychonomic Science, 1970, 19, 363-364.

Graham, F. K., \& Jackson, J. C. Arousal systems and infant heart rate responses. In L. P. Lipsitt \& H. W. Reese (Eds.), Advances in child development and behavior (Vol. 5). New York: Academic Press, 1970.

Graham, F. K., Leavitt, L. A., Strock, B. D., \& Brown, J. W. Precocious cardiac orienting in a human anencephalic infant. Science, 1978, 199, 322-324.

GreY, J. M. Multidimensional perceptual scaling of musical timbres. Journal of the Acoustical Society of America, 1977, 61, $1270-1277$.

Grey, J. M., \& Gondon, J. W. Perceptual aspects of spectral modifications on musical timbres. Journal of the Acoustical Society of America, 1978, 63, 1493-1500.

Grey, J. M., \& Moore r, J. A. Perceptual evaluation of syn- thesized musical instrument tones. Journal of the Acoustical Society of America, 1977, 62, 454-462.

Hale, G. A. On the use of ANOVA in developmental research. Child Development, 1977, 48, 1101-1106.

HÉCAEN, H. Acquired aphasia in children and the ontogenesis of hemispheric functional specialization. Brain \& Language, 1976, 3, 114-134.

Hier, D. B., Le May, M., \& Rosenberger, P. B. Autism and unfavorable left-right asymmetries of the brain. Journal of Autism and Developmental Disorders, 1979, 9, 153-159.

Hutt, S. J., Hutr, C., Lenard, H. G., von Bernuth, H., \& MuntJewerfF, W. J. Auditory responsivity in the human neonate. Nature, 1968, 218, 888-890.

Johansson, G. Visual perception of biological motion and a model for its analysis. Perception \& Psychophysics, 1973, 14, 201-211.

KrmurA, D. Speech lateralization in young children as determined by an auditory test. Journal of Comparative and Physiological Psychology, 1963, 56, 899-901.

Kimura, D. Left-right differences in the perception of melodies. Quarterly Journal of Experimental Psychology, 1964, 14, 355-358.

Kimura, D. Functional asymmetry of the brain in dichotic listening. Cortex, 1967, 3, 163-178.

Kinsbourne, M., \& Hiscock, M. Ontogeny of cerebral dominance. In S. J. Segalowitz \& F. A. Gruber (Eds.), Language development and neurological theory. New York: Academic Press, 1977.

Kır, R. E. Experimental design: Procedures for the behavioral sciences. Belmont, Calif: Wadsworth, 1968.

KNox, A. W., \& KimunA, D. Cerebral processing of nonverbal sounds in boys and girls. Neuropsychologia, 1970, 8, 227-238.

Kohn, B., \& DEnNis, M. Selective impairments of visuo-spatial abilities in infantile hemiplegics after right cerebral decortication. Neuropsychologia, 1974, 12, 505-512.

Levitt, L. A., Brown, J. W., Morse, P. A., \& Graham, F. K. Cardiac orienting and auditory discrimination in 6-week-old infants. Developmental Psychology, 1976, 12, 514-523.

Leavitt, L. A., Morse, P. A., Brown, J. W., \& Graham, F. K. Cardiac orienting to speech and nonspeech stimuli in six-week-old infants. Pediatric Research, 1973, 7, 419.

LEE, D. Visuo-motor coordination in space-time. In G. Stelmach \& J. Requin (Eds.), Tutorials in motor behavior. Amsterdam: North-Holland, 1980.

Lennebero, E. H. Biological foundations of language. New York: Wiley, 1967.

LEVY, J. Cerebral asymmetry and the psychology of man. In M. C. Wittrock (Ed.), The brain and psychology. New York: Academic Press, 1980.

Levy-Agresti, J., \& Sperry, R. Differential perceptual capacities in major and minor hemispheres. Proceedings of the National Academy of Sciences, 1968, 61, 1151.

MCCall, R. B., \& Melson, W. H. Amount of short term familiarization and the response to auditory discrepancies. Child Development, 1970, 41, 861-869.

Michaels, C. F., \& Carello, C. Direct perception. Englewood Cliffs, N.J: Prentice-Hall, 1981

Miller, C. L., Morse, P. A., \& Dorman, M. F. Cardiac indices of infant speech perception: Orienting and burst discrimination. Quarterly Journal of Experimental Psychology, 1977, 29, 533545.

Millek, J. R., \& Carterette, E. C. Perceptual space for musical structures. Journal of the Acoustical Society of America, 1975, 58, 711-720.

Milner, B. Hemispheric specialization. In F. O. Schmitt \& F. G. Worden (Eds.), The neurosciences: Third study program. Cambridge, Mass: M.I.T. Press, 1974.

Molfese, D. L., Freeman, R. B., \& Palermo, D. S. The ontogeny of brain lateralization for speech and nonspeech stimuli. Brain \& Language, 1975, 2, 356-368.

Molfese, D. L., \& Molfese, V. J. Hemisphere and stimulus 
differences as reflected in the cortical responses of newborn infants to speech stimuli. Developmental Psychology, 1979, 15, 505-511. (a)

Molye 8E, D. L., \& Mot.fese, V. J. Infant speech perception: Learned or innate? In H. A. Whitaker \& H. Whitaker (Eds.), Studies in neurolinguistics (Vol. 4). New York: Academic Press, 1979. (b)

Molfese, D. L., \& Molfese, V. J. Cortical responses of preterm infants to phonetic and nonphonetic speech stimuli. Developmental Psychology, 1980, 16, 547-581.

Molfege, D. L., Nunez, V., Seibert, S. M., \& Ramaniah, N. V. Cerebral asymmetry: Changes in factors affecting its development. Annals of the New York Academy of Sciences, 1976, 280, 821-833.

Morse, P. A. The discrimination of speech and nonspeech stimuli in early infancy. Journal of Experimental Child Psychology, $1972,14,477-492$.

Morse, P. A. Infant speech perception: Origins, processes, and Alpha Centauri. In F. Minifie \& L. Lloyd (Eds.), Communicative and cognitive abilities: Early behavioral assessment. Baltimore: University Park Press, 1978.

Natale, M. Perception of nonlinguistic auditory rhythms by the speech hemisphere. Brain \& Language, 1977, 4, 32-44.

Oden, G. C., \& Massaro, D. W. Integration of featural information in speech. Psychological Review, 1978, 85, 172-191.

Rasmussen, T., \& Milner, B. The role of early left-brain injury in determining lateralization of cerebral speech functions. Annals of the New York Academy of Sciences, 1977, 299, 355-369.

ROEDERER, J. G. Introduction to the physics and psychophysics of music. New York: Springer-Verlag, 1973.

RUFF, H. A. The development of perception and recognition of objects. Child Development, 1980, 51, $981-992$.

Schwartz, J., \& Tallal, P. Rate of acoustic change may underlie hemispheric specialization for speech perception. Science, $1980,207,1380-1381$.

Seamon, J. G., \& Gazzaniga, M. S. Coding strategies and cerebral laterality effects. Cognitive Psychology, 1973, 5, 249-256.

Segalowitz, S. J., \& Chapman, J. S. Cerebral asymmetry for speech in neonates: A behavioral measure. Brain \& Language, $1980,9,281-288$.

Semmes, J. Hemispheric specialization: A possible clue to mechanism. Neuropsychologia, 1969, 6, 11-26.

Shankweiler, D. Effects of temporal lobe damage on perception of dichotically presented melodies. Journal of Comparative and Physiological Psychology, 1966, 62, 115-119.

Simon, N. Echolalic speech in childhood autism: Consideration of possible underlying loci of brain damage. Archives of General Psychiatry, 1975, 32, 1439-1446.

SPELKe, E. S. Exploring audible and visible events in infancy. In A. D. Pick (Ed.), Perception and its development. New York: Halsted Press, 1979.

Spellacy, F., \& Blumstein, S. The influence of language set on ear preference in phoneme recognition. Cortex, 1970, 6, 430-439.

Studdert-Kennedy, M., \& Shankweller, D. Hemispheric specialization for speech perception. Journal of the Acoustical Society of America, 1970, 48, 579-594.

Summerfield, A. Q. Perceptual learning and phonetic perception. Interrelations of the communicative senses: Proceedings of the 1978 NSF conference at Asilomar, California. Washington, D.C: NSF Publications, 1978.

TAkagi, $R$. [Language developmental disorder as the primary disturbance of childhood autism.] Japanese Journal of Child Psychiatry, 1972, 13, 285-294.

Tanauny, P. E. Clinical and electrophysiological research. In E. R. Ritvo, B. J. Freeman, E. M. Ornitz, \& P. E. Tanguay (Eds.), Autism: Diagnosis, current research and management. New York: Spectrum, 1976.

TAYLon, D. C. Differential rates of cerebral maturation between sexes and between hemispheres. Lancet, 1969, 11, 140-142.
Tombinson-Keasey, C., Kelly, R., \& Burton, J. K. Hemispheric changes in information processing during development. Developmental Psychology, 1978, 14, 214-223.

Trehub, S. E., \& Rabinovitch, M. S. Auditory-linguistic sensitivity in early childhood. Developmental Psychology, 1972, 6, 74-77.

Trevarthen, C. The psychobiology of speech development. In E. H. Lenneberg (Ed.), Language and brain: Developmental aspects. Neurosciences Research Program Bulletin, 1977, 12 , 512-666. (a)

Trevarthen, C. Descriptive analyses of infant communicative behavior. In H. R. Schaffer (Ed.), Studies in mother-infant interaction. New York: Academic Press, 1977. (b)

Vargha-Khadem, F., \& Corballis, M. Cerebral asymmetry in infants. Brain \& Language, 1979, 8, 1-9.

VEROFF, A. A structural determinant of hemispheric processing of pictorial stimuli. Brain \& Language, 1978, 5, 139-148.

Wessel, D., Smith, B., \& Ehresman, D. Psychoacoustic experimentation as a prelude to musical composition. Journal of the Acoustical Society of America, 1978, 64 (Suppl.), S170. (Abstract)

WITELson, S. Early hemisphere specialization and interhemispheric plasticity: An empirical and theoretical review. In S. J. Segalowitz \& F. A. Gruber (Eds.), Language development and neurological theory. New York: Academic Press, 1977.

ZAtorRe, R. J. Recognition of dichotic melodies by musicians and nonmusicians. Neuropsychologia, 1979, 17, 607-618.

\section{NOTES}

1. Although seemingly high, this rate is in line with other cardiac habituation studies of young infants; reported rejection rates have even been as high as $\mathbf{9 0 \%}$ (Morse, 1972). The attrition problem, and the selection biases it may introduce, are well recognized in infant research; unfortunately, no completely satisfactory solution has been found.

2. Both the speech and music stimuli were the same as those used in the Glanville et al. (1977) study.

3. The alpha levels were set at the standard .05, rather than adjusted upward, for the following reasons: (1) these were planned comparisons, (2) the $n$ for each age group was small (16), (3) the statistical likelihood of obtaining the full pattern of predicted results across all age-specific tests was extremely low, and (4) the predictions included not only significant effects, but also lack of certain effects (in 2-month-olds); these considerations all reduce the probability of Type I error and increase the probability of Type II error. Further reduction of Type I probability through alpha-level adjustment was deemed unnecessary.

4. A significant stimulus type effect $[F(1,42)=7.83, p<.007]$ in the difference score analysis suggested that cardiac ORs were larger for speech than for music note presentations, which was supported by a stimulus type $x$ pre-post interaction $[F(1,42)=$ $6.63, p<.025]$ in the pre-post analysis. Whereas prestimulus heart rates did not differ significantly for the two stimulus types, poststimulus heart rate was lower for speech syllables than for music notes $[F(1,84)=4.65, p<.05]$. Nonetheless, the pre-post effect $[F(1,42)=91.37, p<.0001]$ showed that the prestimulus vs. poststimulus heart rate difference was significant (reliable cardiac OR) for both music $[F(1,84)=13.918, p<.001]$ and speech presentations $[F(1,84)=38.44, p<.0001]$ during the habituation trials.

5. There was a significant age effect in the difference score analysis $[F(1,42)=14.34, p<.005]$ and an age $x$ pre-post interaction in the pre-post analysis $[\mathrm{F}(2,42)=3.81, \mathrm{p}<.05]$. Tonic rate decreased with age, whereas $O R$ magnitude increased with age, in keeping with data on the early ontogeny of stimulus-elicited cardiac responses (e.g., Graham, Berg, Berg, Jackson, \& Kantowitz, 1970; Graham \& Jackson, 1970). Planned comparison t tests revealed a significant difference in average heart rate between 2 - and 3 -month-olds $(t=10.59, p<.05)$ and between 2 - and 4-month-olds $(t=17.85, p<.01)$ but not between 3 - and 4 -month olds. 


\section{APPENDIX}

To determine individual asymmetries, we classified each infant's ear differences in Trial 10 dishabituation, relative to Trial 9 responses, within each stimulus type. The criteria were: (1) Trial 10 deceleration of $>$ or $=+.5 \mathrm{BPM}$ (difference score); (2) Trial 10 deceleration at least .5 BPM greater than the Trial 9 difference score; (3) criteria 1 and 2 fit at least one test within a stimulus type; and (4) at least a .5 BPM ear difference in dishabituation.

The infants who dishabituated on at least one test within a stimulus type had ear symmetries of at least .8 BPM (most were much larger), except for one 3-month-old who showed equal-ear OR recovery on the speech tests. The proportion of music LEAs, and speech REAs, were both significant $(z=1.92, p<.053)$. Thirty-three of the 48 infants discriminated music timbre, with an LEA in $22(67 \%)$, which agrees with the proportion of music LEAs among normal adults (e.g., Zatorre, 1979). In addition, 24/33 $(73 \%$ ) infants showed a speech REA (not the same 33 as in the music tests). This is smaller than the $80 \%$ of righthanded adults who typically show a speech REA (e.g., Kimura, 1967), but our analysis included the 2-month-olds, who did not show a consistent group REA for speech. Of the 3- and 4-month-olds alone, 18/24 showed a speech REA
$(75 \%)$. Moreover, the eventual handedness of these older infants is unknown, and the incidence of left-hemisphere speech dominance among adult left-handers is only $60 \%$ (e.g., Goodglass \& Quadfasel, 1954). An estimated 7\%$10 \%$ population proportion of left-handers suggests that perhaps 2 of the 24 older infants will become left-handed, only one of whom might show a speech REA. Thus, 22 of those 24 infants should become right-handed, with an REA in 17 , or $77.3 \%$; this proportion agrees more closely with the right-handed adult incidence.

The age breakdown was: a music LEA in 6/8 $(75 \%)$ of the 2-month-olds and a speech REA in 6/9 $(67 \%)$. Their OR recoveries on the speech tests were small, however, while those for the left-ear music tests were larger, as would be expected from the parametric analyses. Ten of 153 month-olds (67\%) showed a music LEA, and 12/13 $(92 \%)$ showed a speech REA, with equal-ear speech discrimination in the 13th infant $(8 \%)$. Of the 4-month-olds, $6 / 10$ $(60 \%)$ showed a music LEA, while 6/11 $(55 \%)$ showed a speech REA. Among the 4-month-olds, the speech REAs were substantially larger than the LEAs.

(Manuscript received May 12, 1981;

revision accepted for publication October 6, 1981.) 